\title{
How did the 2011 off the Pacific coast of Tohoku Earthquake start and grow? The role of a conditionally stable area
}

\author{
Yuta Mitsui* and Yoshihisa Iio \\ Research Center for Earthquake Prediction, Disaster Prevention Research Institute, Kyoto University, Uji 611-0011, Japan
}

(Received April 7, 2011; Revised May 5, 2011; Accepted May 13, 2011; Online published September 27, 2011)

\begin{abstract}
The 2011 off the Pacific coast of Tohoku Earthquake broke a huge area of the plate interface; such a large event has not been observed before off the Pacific coast of Japan. We propose a preliminary scenario of the generation mechanism of the $M_{\mathrm{w}} 9$ earthquake, referring to geophysical observation data: In the restoration period of the interplate locking after the active period of $M$ 7-class earthquakes and afterslip, one $M$ 7-class earthquake off Miyagi occurred. It could have triggered the 2011 Tohoku Earthquake as in the model proposed by Matsuzawa et al. (2004). The seismic slip from the northern part propagated through a barrier-like region, which had been almost locked except the afterslip of the $M$ 7-class earthquakes, and extended to the southern part. We present a preliminary numerical simulation to show that the extremely large slip in the northern part was able to cause the seismic slip without large-scale nucleation over the whole fault. The interseismic and coseismic slip behavior of the barrier-like region is well explained by a "conditionally stable" condition of frictional instability. Since the present simulation does not allow us to explain the generation mechanism of the extremely large slip in the northern part of the $M 9$ fault, we need to construct a more detailed model in future studies.
\end{abstract}

Key words: Earthquake cycle, giant earthquake, aseismic slip, conditionally stable, rate and state friction.

\section{Introduction}

Coseismic rupture of the 2011 off the Pacific coast of Tohoku Earthquake broke an area on the subduction plate boundary east of northern Honshu. The ruptured area was estimated to be as large as $450 \mathrm{~km} \times 200 \mathrm{~km}$ (Yagi and Nishimura, 2011). The moment magnitude determined by the Japan Meteorological Agency (JMA) was 9.0. This is much larger than the "expected" $M$ 7-class earthquakes (and even $M$ 8-class synchronized earthquakes) on the asperities of the Off-Miyagi Prefecture (e.g., Yamanaka and Kikuchi, 2004).

With regard to the "expected" earthquakes, Matsuzawa et al. (2004) earlier proposed that quasi-static slip, namely large afterslip of large earthquakes, partly compensates slip deficits on non-asperity regions with expansion of aftershock activity, and can trigger even larger earthquakes. The model of Matsuzawa et al. (2004) explains the distribution of quasi-static slip estimated by analyses of small repeating earthquakes on the plate boundary and GPS data (Igarashi et al., 2003). Can we adopt their conceptual model for understanding the devastating 2011 Tohoku Earthquake? To answer this question, we first examine observational data.

Mechanical models of earthquake cycles including interseismic, coseismic, and postseismic evolution of fault slip

\footnotetext{
*Now at Department of Natural History Sciences, Graduate School of Science, Hokkaido University, Sapporo 060-0810, Japan.

Copyright (c) The Society of Geomagnetism and Earth, Planetary and Space Sciences (SGEPSS); The Seismological Society of Japan; The Volcanological Society of Japan; The Geodetic Society of Japan; The Japanese Society for Planetary Sciences; TERRAPUB.

doi:10.5047/eps.2011.05.007
}

have been developed to simulate such earthquake activities on multiple asperities (Kato, 2008; Ariyoshi et al., 2009; Hori et al., 2009). Hence, mechanical models with a rateand state-dependent friction law are useful for considering the generation mechanism of the 2011 Tohoku Earthquake. In particular, these types of mechanical models include the early phase of nucleation (creep propagation from fault edges) during interseismic periods, which is related to fault instability (Mitsui and Hirahara, 2011). The early nucleation could have been detected by geophysical observations, if it had occurred over the whole fault of the $M 9$ earthquake.

Here, we examine geophysical data with regard to the 2011 Tohoku Earthquake, test the hypothesis of Matsuzawa et al. (2004), and propose a preliminary scenario of the generation mechanism of the devastating earthquake. Then we will try to construct a numerical model for the mechanical system of the giant $M 9$ earthquake.

\section{What Is Implied by Geophysical Observation?}

2.1 Coseismic process

Referring to seismic inversions by several researchers (e.g. Yagi and Nishimura, 2011; Kiser and Ishii, 2011), we have a qualitative common image of the coseismic rupture. The rupture started from the hypocenter approximately at $38^{\circ} \mathrm{N}, 143^{\circ} \mathrm{E}$, and first broke the northern part of the fault off Miyagi (and Sanriku) with large slip, and next extended to the southern part, off Fukushima and Ibaraki. Such a large-scale rupture, which led to the $M$ 9-class earthquake, has not been observed before off the Pacific coast of Japan. In particular, the coseismic slips both in the regions off Miyagi and off Fukushima-Ibaraki are the largest 


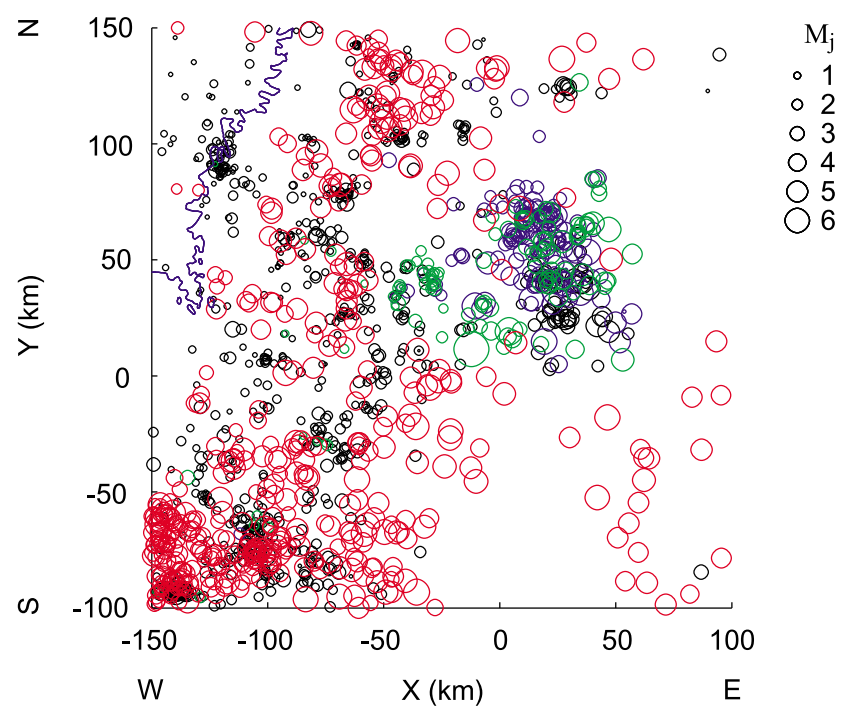

01-Feb-2011 00:00:00 - 09-Mar-2011 11:44:59

09-Mar-2011 11:45:00 - 10-Mar-2011 06:22:59

10-Mar-2011 06:23:00 - 11-Mar-2011 14:46:59 11-Mar-2011 14:47:00 - 25-Mar-2011 23:59:59

Fig. 1. The spatiotemporal distribution of the hypocenters determined by JMA, from February 1 to March 25. The origins of longitude ( $x$-axis) and latitude ( $y$-axis) are at $143^{\circ} \mathrm{E}$ and $38^{\circ} \mathrm{N}$, which almost corresponds to the hypocenter of the 2011 Tohoku Earthquake. The period is divided into four terms: From February 1 to the occurrence of the $M_{\mathrm{j}} 7.3$ earthquake (on March 9), from the occurrence of the $M_{\mathrm{j}} 7.3$ earthquake to its largest aftershock (on March 10), from the occurrence of the largest aftershock to the 2011 Tohoku Earthquake (on March 11), and after the occurrence of the $M_{\mathrm{j}} 7.3$ earthquake. The aftershock area of the $M_{\mathrm{j}} 7.3$ earthquake horizontally expanded next to the hypocenter of the 2011 Tohoku Earthquake, just before its occurrence.

ever observed. Therefore we need to consider at least three regions on the fault. Region 1 represents the area off Miyagi with a historical sequence of $M 7$-class earthquakes (Yamanaka and Kikuchi, 2004; Kanamori et al., 2006), Region 2 is the area that had not been previously ruptured coseismically by $M$ 7-class earthquakes (therefore, hereinafter called the barrier-like region), and Region 3 comprised the area off Fukushima and Ibaraki, where several $M 7$-class earthquakes occurred during the last hundred years (e.g. Abe, 1977). In the following discussion, we refer to this classification of the region.

\subsection{Preseismic process (1-month scale)}

A large interplate earthquake $\left(M_{\mathrm{j}} 7.3\right)$ occurred on March 9, off Miyagi near the hypocenter of the 2011 Tohoku Earthquake. It preceded the 2011 Tohoku Earthquake on March 11 by two days.

Figure 1 shows the spatiotemporal distribution of the hypocenter determined by JMA, from February 1 to March 25 . The origins of longitude ( $x$-axis) and latitude ( $y$-axis) are at $143^{\circ} \mathrm{E}$ and $38^{\circ} \mathrm{N}$, which almost corresponds to the hypocenter of the 2011 Tohoku Earthquake. The plotted area includes Regions 1 and 2. We can infer that the hypocenter of the 2011 Tohoku Earthquake is located at the edge of the expanded aftershock area of the March 9 earthquake, although the JMA data is less than perfect at this moment. Moreover, a borehole strainmeter at Kinkazan, on the coast of Miyagi, detected postseismic deformation after the March 9 earthquake (Tohoku University, 2011). Since the strainmeter was able to detect afterslip of $M 7$-class earthquakes off Miyagi and Fukushima (Mishina et al., 2009), this observation indicates the existence of afterslip of the March 9 earthquake. Furthermore, GPS data analysis by the Geospatial Information Authority of Japan (GSI) also revealed the postseismic deformation at some stations on the coast (GSI, 2011). The amounts of the observed postseismic deformation were several tens of percentage of the coseismic deformation at the March 9 earthquake. The observations of the aftershock expansion and afterslip support the applicability of the Matsuzawa et al.'s (2004) model to the $M 9$ Tohoku Earthquake.

\subsection{Preseismic process (10-year scale)}

Large area on the plate inferface off the Pacific coast of Tohoku, roughly including the entire fault of the 2011 Tohoku Earthquake, was estimated to be strongly coupled by GPS data inversion (Ito et al., 2000). The period which they investigated is 1996 to 1998. Suwa et al. (2006) also estimated the large slip deficits over a period of 1997-2001. In their results, the extent of the coupled (>50\%) area was about $250 \mathrm{~km} \times 200 \mathrm{~km}$ stretching from off Miyagi region.

Besides, Uchida et al. (2006) and Tohoku University (2009) estimated the spatiotemporal evolution of the quasistatic slip on the fault area of the 2011 Tohoku Earthquake, using small repeating earthquakes. Their results showed that the quasi-static slip on certain regions was accelerated by afterslip of $M 7$-class earthquakes (for example; Fukushima-Oki, on October 31, 2003, in region 1; MiyagiOki, on August 16, 2005, in region 1; Ibaraki-Oki, on May 8, 2008 in region 3; Fukushima-Oki, July 19, 2008, in region 3). Kinematic slip inversion using GPS data also revealed the large afterslip, for example, following the 2005 Miyagi-Oki earthquake (Miura et al., 2006).

Then, until the occurrence of the earthquake in region 1 on March 9, 2011, the interplate locking (small slip amount relative to the plate convergence) seemed to be restored over the fault (Tohoku University, 2009) after the decay of those afterslip. In particular, off Miyagi region near the hypocenter of the $M 9$ Tohoku Earthquake, locking was clearly restored as revealed by GPS/acoustic seafloor geodetic observation (Sato et al., 2011). These observations suggest that the early phase of nucleation over the whole fault of the $M 9$ earthquake did not occur at least in the simple way as Mitsui and Hirahara (2011) investigated.

\subsection{Scenario for the occurrence of the 2011 Tohoku Earthquake}

From the above observations, we construct a preliminary scenario of the generation mechanism of the 2011 Tohoku Earthquake as follows.

Each active part of the fault, separated by barrier-like regions, held its own seismic activity. Namely Region 1 had a complex sequence of the $M$ 7-class earthquakes (e.g. Kanamori et al., 2006). Region 3 had also a sequence of the M 7-class earthquakes (e.g. Abe, 1977). The whole fault was almost entirely locked as shown by the GPS inversion studies (e.g. Ito et al., 2000) before 2003.

During the period 2003-2008, several M 7-class earthquakes occurred and their afterslip propagated through a 
wide area on the fault of the 2011 Tohoku Earthquake. The afterslip caused local acceleration of relative slip on the plate interface, which was a transient weak coupling. Then the interplate locking was restored all around.

On March 9, 2011, another M 7-class earthquake occurred within Region 1, and its afterslip accompanying the expansion of aftershocks led to the 2011 Tohoku Earthquake on March 11. The coseismic slip first ruptured Region 1 with extremely large slip, propagated through the barrier-like Region 2, and finally broke Region 3.

\section{Preliminary Numerical Model}

\subsection{Aim of modeling}

Following the scenario given above, we try to model a mechanical system of the $M 9$ Tohoku Earthquake. As a first result, we use a system of three-degrees-of freedom, which assumes Blocks 1-3 for the Regions 1-3 governed by a rate- and state-dependent friction law with the aging type of the state evolution law and radiation damping (e.g. Rice, 1993). The blocks are connected to each other by springs and pulled at a steady rate of the plate convergence, $10 \mathrm{~cm} /$ year. Our model is similar to that of Kanu and Johnson (2011), but we set a spring between Blocks 1 and 3 as the elastic force at a distance. Figure 2 illustrates the model set-up.

We aim at simulating several aspects of the scenario: (1) All of the regions (blocks) are almost locked except during the periods of coseismic slip and afterslip. (2) Seismic slip events at Region 3 cause an afterslip in Region 2, but do not lead to instantaneous triggering of seismic events in Regions 2 and 1. (3) Seismic slip events having an extremely large slip that occurred in Region 1 extend to Regions 2 and 3, and cause a seismic slip there. Because of the model simplicity, we do not consider other scenarios in our modeling; in particular, the earthquake sequence within Region 1 (e.g., the March 9 earthquake).

\subsection{Results}

In order to carry out numerical simulations, we choose frictional parameters $A, B$, and $L$ for the Blocks 1 and 3 to be in unstable conditions (sufficiently large $(B-A) / L$ ), where $A$ means the multiplication of $a$ by normal stress and $B$ is that for $b$. $a$ and $b$ are frictional parameters for a rate- and state-dependent friction law (Ruina, 1983). In particular, we assume a rather large $B-A$ for Block 1 to cause extremely large slip within the framework of the rate and state law. By contrast, for the middle Block 2, we should set a "not unstable" condition, since no spontaneous slip events occur at this block. If $B \ll A$ is assumed, the condition is "strongly stable". However, such a condition does not represent the first aspect of our scenario (i.e., all of the blocks are almost locked). Therefore, we should set the "conditionally stable" condition, by $B \simeq A$ (Boatwright and Cocco, 1996), at Block 2. In particular, we found that $B=A$ (velocity-neutral condition) at Block 2 explains well the above behavior. We have confirmed by trial calculations that $B<A$ leads to weak coupling during interseismic periods, and $B>A$ leads to spontaneous occurrence of slow slip events (corresponding to the result by Yoshida and Kato (2003)).

Figure 3 shows a calculation result of temporal slip evo-

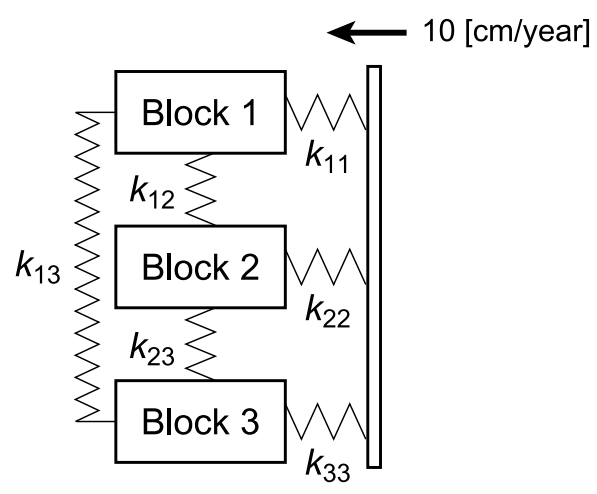

Fig. 2. Mechanical system of springs and blocks used in this study. Three blocks (representing the three regions of the fault of the 2011 Tohoku Earthquake) are connected to each other by springs, and loaded by slip deficits from the plate convergence, 10 [cm/year]. The rate and state friction law is applied to friction between the blocks and the background.

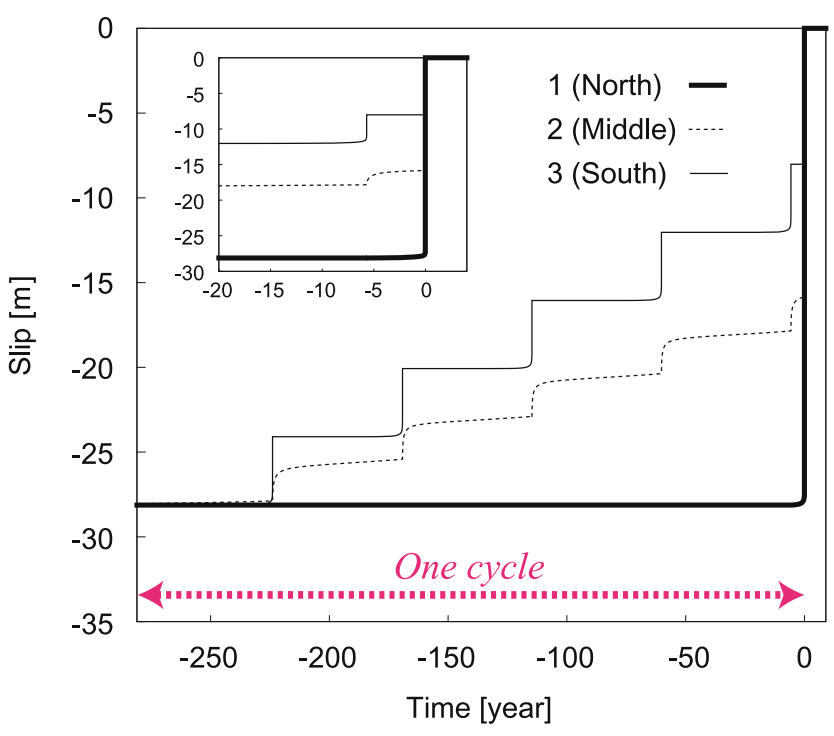

Fig. 3. Temporal evolution of the slip of the three blocks during one cycle of giant events, when we assume the parameters shown in Table 1. Relative time from the end of a giant event (occurs at Block 1 and involves all the blocks) are plotted on the horizontal axis, and relative slip from the end of the giant event are plotted on the vertical axis. The recurrence interval of the giant event is approximately 281 years, and that of the ordinary event (occurs at Block 3 and causes afterslip at Block 2) is 55 years. The coseismic slip in the giant event is largest at Block 1, second largest at Block 2, and smallest at Block 3. Even the smallest slip at Block 3 is larger than that in the ordinary event. In the inset figure, the slip evolution before the occurrence of the giant event is plotted in close-up.

lution after many earthquakes from the beginning of the calculation, sufficiently long to remove the effects of initial conditions, when we assume the parameters described in Table 1. Blocks 1 and 3 have their characteristic recurrence intervals of spontaneous slip events, but only the events at Block 1 involve a seismic slip all over the fault.

Our model succeeded in simulating the following behavior: (1) All of the blocks are strongly coupled (nearly zero slip) except during the periods of coseismic slip and afterslip. (2) Seismic slip events at Block 3 cause an afterslip at Block 2, but do not lead to the instantaneous triggering of seismic events at Blocks 2 and 1. (3) Seismic slip events 
Table 1. Parameters used in this study. The meanings of the parameters are the same as those in previous studies (e.g., Mitsui and Hirahara, 2009). The $S$-wave velocity is 3000 [m/s] and the rigidity is 27 [GPa]. In addition, $A$ means the multiplication of $a$ by normal stress, and $B$ is that of $b$.

\begin{tabular}{ccccc}
\hline & $A[\mathrm{MPa}]$ & $B[\mathrm{MPa}]$ & $L[\mathrm{~m}]$ & Stiffness $[\mathrm{MPa} / \mathrm{m}]$ \\
\hline Block 1 & 0.5 & 2.5 & 0.42 & 0.381 \\
Spring (1-2) & & & & 0.133 \\
Block 2 & 0.25 & 0.25 & 0.5 & 0.053 \\
Spring (2-3) & & & & 0.133 \\
Block 3 & 0.4 & 0.8 & 0.15 & 0.533 \\
Spring (1-3) & & & & 0.114 \\
\hline
\end{tabular}

with extremely large slip that occurred at Block 1 extend to Blocks 2 and 3, and cause seismic slip there. The maximum slip velocity at each block is different. Those velocities for Blocks 1, 2, and 3 are approximately $6.6,0.9$, and $1.9 \mathrm{~m} / \mathrm{s}$, respectively. The maximum slip velocity at Block 2 is relatively small, which could be related to differences between seismological and geodetic observations.

\subsection{Discussion}

The simplicity of our present model limited the simulation to a sketch. In fact, the steady recurrence of the $M 9$ event from Region 1 seems unrealistic. To consider the earthquake sequence within Region 1 (e.g., the March 9 earthquake) would be needed. Moreover, how the coseismic slip of the $M 9$ earthquake in Region 1 was much larger than the usual Miyagi-Oki earthquakes is an important issue. Although several processes may explain this, one plausible process is a dynamic fault weakening other than the rate and state friction. For example, once the coseismic slip evolves in a fluid-saturated fault, thermal pressurization of pore fluid (e.g., Mitsui and Hirahara, 2009) can operate as a dynamic process to promote seismic slip even on a weak fault with a low absolute level of stress. In addition, stress accumulation due to the sequence of $M 7$-class earthquakes since 2003 might cause the effective thermal pressurization locally, enhance propagation of dynamic rupture and moment release within Region 1 . Such a system will be implemented into subsequent simulations.

\section{Conclusion}

From implications based on geophysical data, we have proposed a preliminary scenario of the generation mechanism of the 2011 Tohoku Earthquake. In the restoration period of interplate locking after the active period of $M 7$ class earthquakes accompanying afterslip, one $M$ 7-class earthquake occurred off Miyagi on March 9, 2011. This could have triggered the 2011 Tohoku Earthquake according to the model proposed by Matsuzawa et al. (2004). The coseismic slip first ruptured the northern part off Miyagi, then propagated through the barrier-like region, which had been almost locked except during the active period of $M 7$ class earthquakes, and finally broke the southern part off Fukushima and Ibaraki. We have constructed a preliminary numerical model of the mechanical system of the 2011 Tohoku Earthquake which shows that the extremely large slip in the northern part was able to involve seismic slip without the early phase of nucleation (weakening of the inter- plate locking) over the whole fault. The slip behavior of the barrier-like region can be explained by a "conditionally stable" condition of frictional instability. However, in order to explain the mechanism of the extremely larger slip in the northern part of the $M 9$ fault, than the usual $M$ 7-class earthquakes, we need to construct a more detailed model.

Acknowledgments. We are grateful for comments by Kazuro Hirahara, Yukitoshi Fukahata, Kosuke Heki, and Kiyoshi Yomogida, and for reviews by Naoyuki Kato, Takane Hori, and Hiroo Kanamori. We also thank the Japan Meteorology Agency (JMA) for providing us the unified catalog for this study (part of the hypocenter data is preliminary).

\section{References}

Abe, K., Tectonic implications of the large Shioya-oki earthquakes of 1938, Tectonophysics, 41, 269-289, 1977.

Ariyoshi, K., T. Matsuzawa, Y. Yabe, N. Kato, R. Hino, A. Hasegawa, and Y. Kaneda, Character of slip and stress due to interaction between fault segments along the dip direction of a subduction zone, J. Geodyn., 48, 55-67, 2009.

Boatwright, J. and M. Cocco, Frictional constraints on crustal faulting, $J$ Geophys. Res., 101(B6), 13895-13909, 1996.

GSI, Seismic activity for March 2011 (April 11, 2011), http://www jishin.go.jp/main/chousa/11apr/p05.htm, 2011.

Hori, T., S. Miyazaki, and N. Mitsui, A model of earthquake-generation cycle with scale-dependent frictional property-Preliminary results and research plan for a project of evaluation for coming Tokai, Tonankai, and Nankai earthquakes, J. Disaster Res., 4, 111-117, 2009.

Igarashi, T., T. Matsuzawa, and A. Hasegawa, Repeating earthquakes and interplate aseismic slip in the northeastern Japan subduction zone, $J$. Geophys. Res., 108(B5), 803-811, doi:10.1029/2002JB001920, 2003.

Ito, T., S. Yoshioka, and S. Miyazaki, Interplate coupling in northeast Japan deduced from inversion analysis of GPS data, Earth Planet. Sci. Lett., 176, 117-130, 2000.

Kanamori, H., M. Miyazawa, and J. Mori, Investigation of the earthquake sequence off Miyagi prefecture with historical seismograms, Earth Planets Space, 58, 1533-1541, 2006.

Kanu, C. and K. Johnson, Arrest and recovery of frictional creep on the southern Hayward fault triggered by the 1989 Loma Prieta, California, earthquake and implications for future earthquakes, J. Geophys. Res., 116, B04403, doi:10.1029/2010JB007927, 2011.

Kato, N., Numerical simulation of recurrence of asperity rupture in the Sanriku region, northeastern Japan, J. Geophys. Res., 113, B06302, doi:10.1029/2007JB005515, 2008.

Kiser, E. and M. Ishii, Preliminary rupture modelling of the March 11, 2011 Tohoku-Chiho Taiheiyo-Oki Earthquake and sequence of events using the USArray transportable array, http://www.seismology.harvard.edu/research_japan.html, 2011.

Matsuzawa, T., N. Uchida, T. Igarashi, T. Okada, and A. Hasegawa, Repeating earthquakes and quasi-static slip on the plate boundary east off northern Honshu, Japan, Earth Planets Space, 56, 803-811, 2004.

Mishina, M., K. Tachibana, and S. Miura, Postseismic deformation associated with off Fukushima earthquakes as inferred data of borehole strainmeters, Geophys. Bull. Hokkaido Univ., 72, 287-298, 2009 (in Japanese with English abstract).

Mitsui, Y. and K. Hirahara, Coseismic thermal pressurization can notably prolong earthquake recurrence intervals on weak rate and state friction faults: Numerical experiments using different constitutive equations, $J$. Geophys. Res., 114, B09304, doi:10.1029/2008JB006220, 2009.

Mitsui, Y. and K. Hirahara, Fault instability on a finite and planar fault related to early phase of nucleation, J. Geophys. Res., 116, B06301, doi:10.1029/2010JB007974, 2011

Miura, S., T. Iinuma, S. Yui, N. Uchida, T. Sato, K. Tachibana, and A Hasegawa, Co- and post-seismic slip associated with the 2005 Miyagioki earthquake (M7.2) as inferred from GPS data, Earth Planets Space, 58, 1567-1572, 2006.

Rice, J. R., Spatio-temporal complexity of slip on a fault, J. Geophys. Res., 98(B6), 9885-9907, 1993.

Ruina, A., Slip instability and state variable friction laws, J. Geophys. Res. 88(B12), 10359-10370, 1983.

Sato, M., H. Sato, T. Ishikawa, Y. Matsumoto, M. Fujita, M. Mochizuki, and A. Asada, Restoration of interplate locking after the 
2005 Off-Miyagi Prefecture earthquake, detected by GPS/acoustic seafloor geodetic observation, Geophys. Res. Lett., 38, L01312, doi:10.1029/2010GL045689, 2011.

Suwa, Y., S. Miura, A. Hasegawa, T. Sato, and K. Tachibana, Interplate coupling beneath NE Japan inferred from three-dimensional displacement field, J. Geophys. Res., 111, B04402, doi:10.1029/2004JB003203, 2006.

Tohoku University, Report on Observation and Research Program for Prediction of Earthquakes and Volcanic Eruptions, No. 1202, 2009 (in Japanese).

Tohoku University, Report on the 190th meeting of the Coordinating Committee for Earthquake Prediction, 12-13, 2011 (in Japanese).

Uchida, N., T. Matsuzawa, S. Hirahara, and A. Hasegawa, Small repeat- ing earthquakes and interplate creep around the 2005 Miyagi-oki earthquake (M=7.2), Earth Planets Space, 58, 1577-1580, 2006.

Yagi, Y. and N. Nishimura, The 2011 Tohoku-oki Earthquake (Ver. 3), http://www.geol.tsukuba.ac.jp/ yagi-y/EQ/Tohoku/, 2011.

Yamanaka, Y. and M. Kikuchi, Asperity map along the subduction zone in northeastern Japan inferred from regional seismic data, J. Geophys. Res., 109, B07307, doi:10.1029/2003JB002683, 2004.

Yoshida, S. and N. Kato, Episodic aseismic slip in a twodegree-of-freedom block-spring model, Geophys. Res. Lett., 30, doi:10.1029/2003GL017439, 2003.

Y. Mitsui (e-mail: ymitsui@mail.sci.hokudai.ac.jp) and Y. Iio 